\title{
The Contributions of Nuclear Medicine in the Diagnosis of Vascular Conditions
}

\author{
Themistoklis Poulios ${ }^{1}$ and Nikolaos Ch Syrmos*2 \\ ${ }^{1}$ Medical Scholl, Univesrity of Thessaly, Greece \\ ${ }^{2}$ Medical Scholl, Aristoteleian Univesrity of Thessaloniki, Greece
}

Received: May 11,2018; Published: May 16, 2018

*Corresponding author: Nikolaos Ch Syrmos, Medical Scholl, Aristoteleian Univesrity of Thessaloniki, PC 54453, Thessaloniki, Macedonia, Greece

\section{Short Communication}

Nuclear medicine is a diagnostic medical specialty that focuses on depicting the function rather than the morphology of certain anatomical structures and organs within the human body with the use of certain radioactive drugs that following the administration to the patient they concentrate on the tissue we want to depict and emit radiation that is detected by a PET or a SPECT scan. This is rather helpful in the case of solid organs and tumorous masses till this day for example the diagnosis of metastases evaluation of coronary artery disease or determination of the type of thyroid nodes but as far as the peripheral vascular system is concerned the use of nuclear medicine was rather limited since the very beginning and hasn't evolved much to this day owning to the fact that vascular diseases are much better depicted with the use of X-ray contrast angiography triplex ultrasound and CT scan. As far as vascular diseases are concerned in the case of peripheral arterial disease the use of scintigraphy is limited for patients who are often elderly and in critical condition and are not good candidates for contrast angiography [1] though recently a case report study by Manevska et al. showed that scintigraphy might be rather helpful with the diagnosis of microangiopathy in diabetic patients [2] as diabetes is responsible for causing both micro and macroangiopathy and contrast angiography does not depict capillaries. Furthermore nuclear medicine doesn't have much to offer in the diagnosis of venooclussive disease taking into consideration the widespread use of duplex and triplex ultrasound which provides great anatomic detail in imaging as opposed to the (99 m) TC-MAA radionuclide venography that can exclude but not diagnose distal venous thrombosis [3]. On the other hand scintigraphy has shown to be rather helpful in the evaluation of vascular graft thrombosis using platelets labeled with Indium-111 [4], the visualization of inflamed thus vulnerable for rupture atherosclerotic plaques using 99mTc-HYNIC-IL-2 [5] that further labels T-lymphocytes inside the inflamed plaque, and the detection of vascular graft infection using labeled white blood cells [6] however having the same sensitivity but additional specificity comparing with CT scan in detecting infected grafts [7]. Finally nuclear medicine has provided some promising results in the determination of the possibility for rupture in aortic aneurisms by detecting increased metabolic process of the aneurismal wall in whole body PET using 18F-fluorodeoxyglucose that has increased uptake in case of metalloproteinase activation by inflammatory cells within the aneurismal wall as shown by Sakalihasan et al. [8].

\section{Reference}

1. Keaveny TV (1986) Contribution of Nuclear Medicine to Vascular Surgery. Eur surg Res 18(3-4): 213-217.

2. Nevena Manevska, Daniela Pop Gjorceva, Irfan Ahmeti, Lidija Todorovska, et al. (2016) Tissue-Muscle Perfusion Scintigraphy of the Lower Limbs in a Patient with Type 2 Diabetes Mellitus and Peripheral Arterial Disease. Mol Imaging Radionucl Ther 25(1): 42-46.

3. Diana Gaitini (2007) Multimodality Imaging of the Peripheral Venous System. Int J Biomed Imaging, pp. 54616.

4. Kessler C, Hardeman MR, Henningsen H, Petrovici J (1990) Clinical Application of Radiolabelled Platelets. Kluwer Academic Pubishers.

5. Marta Opalinska,Tomasz Stompor, Dorota Pach, Renata Mikolajczak, Danuta Fedak Marcin Krzanowski, et al. (2012) Imaging of inflamed carotid artery atherosclerotic plaques with the use of $99 \mathrm{mTc}-\mathrm{HYNIC}-$ IL-2 scintigraphy in end-stage renal disease patients. Eur J Nucl Med Mol Imaging 39(4): 673-682.

6. Lokesh Shahani (2015) Vascular graft infections and role of PET/CT in patients with persistent bacteraemia BMJ Case Rep, pp. bcr 2014207678.

7. Johnson KK, Russ PD, Bair JH, Friefeld GD (1990) Diagnosis of synthetic vascular graft infection: comparison of CT and gallium scans. American Journal of Roentgenology 154(2): 405-409.

8. Natzi Sakalihasan, Roland Hustinx, Raymond Limet (2004) Contribution of PET Scanning to the Evaluation of Abdominal Aortic Aneurysm. Seminars in Vascular Surgery 17(2): 144-153. 


\section{(c) (i) This work is licensed under Creative}

Submission Link: https://biomedres.us/submit-manuscript.php

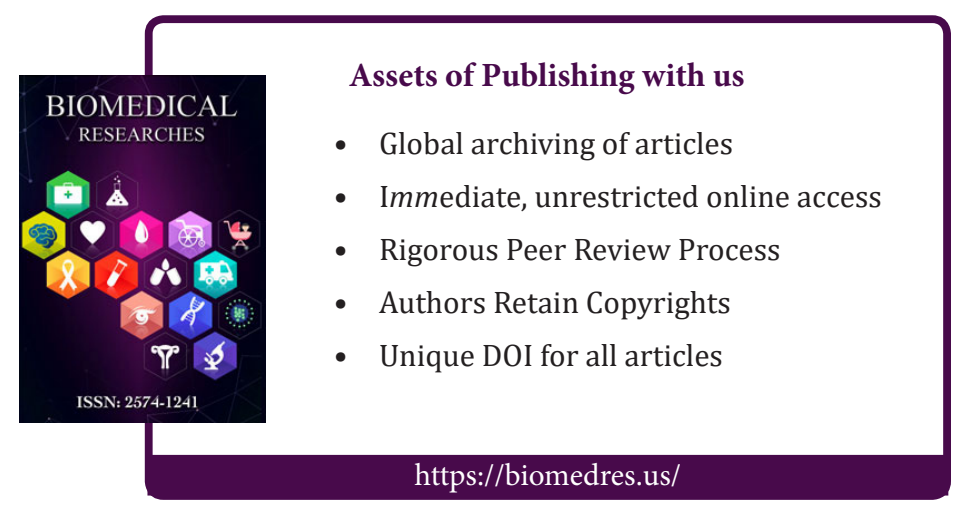

